\title{
Relationship Between the Resting Blood Pressure and Depressor Responses Evoked by Compression of the Eyeballs
}

The relationship between the resting blood pressure and magnitude of pressure responses depends on the kind of stimulus applied for evoking the blood pressure change ${ }^{1,2}$. When the latter is induced by some pharmacological agents, i.e. by noradrenaline or acetylcholine, correlations between these parameters of the pressure response increase with an increase in dose of both drugs ${ }^{3}$. An analogic relationship was studied in some reflex responses ${ }^{4-6}$, but as they were evoked by occlusion of the common carotid or visceral arteries, it was not feasible to determine the effect of afferent stimulation on correlations between the analyzed parameters of the blood pressure response.

In the present investigation, the correlations between the resting blood pressure and magnitude of the reflex depressor responses evoked by the eyeball compression with different intensities were studied in the rabbit. As the previous experiments disclosed some differences in the pattern of activation of the vasomotor centre depending on whether the blood pressure changes were induced by symmetrical or non-symmetrical stimulation of the afferent pathway ${ }^{7}$, these correlations were determined during unilateral and bilateral compression of the eyeballs.

Methods. The experiments were carried out on rabbits under urethane anesthesia. The blood pressure was measured in a common carotid artery. The depressor responses were evoked by compressing the eyeballs according to the method described in the previous study?. This allowed the unilateral or bilateral compression of the eyeballs with a determined strength. In all experiments the duration of stimulation was $20 \mathrm{sec}$ and the time intervals between stimulations were not shorter than $4 \mathrm{~min}$.

Results and discussion. Correlations between the resting blood pressure and magnitude of depressor responses evoked by unilateral (i.e. left side or right side) and bilateral compression of the eyeballs are shown in the Table. The presented data are based on 274 stimulations performed in experiments on 17 rabbits.

It may be seen from the Table that magnitudes of the correlation coefficients ( $r$ ) depend on intensity of the stimulation applied. In the intensity range between 80 and $200 \mathrm{~mm} \mathrm{Hg}$, the increase in strength of stimulation is accompanied by an important increase in values of the correlation coefficients. This indicates that in the above range the greater the strength of afferent stimulation the greater the dependence between the resting blood pressure and magnitude of depressor effects. At the stimulation intensity amounting to $200 \mathrm{~mm} \mathrm{Hg}$, the correlation coefficients attain their maximal value and they become statistically significant, but when the

\begin{tabular}{|c|c|c|c|c|c|c|}
\hline \multirow{2}{*}{$\begin{array}{l}\text { Kind of } \\
\text { stimulation }\end{array}$} & \multicolumn{6}{|c|}{ Strength of compression of eyeballs in $\mathrm{mm} \mathrm{Hg}$} \\
\hline & 80 & 120 & 160 & 200 & 240 & 280 \\
\hline Left & 0.009 & 0.252 & 0.212 & $0.756^{\mathrm{b}}$ & 0.25 & \\
\hline Right eyeball & 0.264 & 0.299 & 0.345 & 0.694 & 0.347 & 0.172 \\
\hline Both eyeballs & -0.247 & 0.245 & 0.307 & $0.605^{\mathrm{a}}$ & 0.454 & 0.517 \\
\hline
\end{tabular}

a $P<0.05 ;$ b $P<0.01$. Correlation coefficients $(\mathrm{r})$ between the resting blood pressure and magnitude of depressor responses evoked by left side, right side and bilateral compression of the eyeballs calculated for 6 intensities of afferent stimulation. strength of stimulation increases up to $240 \mathrm{~mm} \mathrm{Hg}$ they start to decrease. At the greatest stimulation intensity applied, the relationships calculated for bilateral and left side stimulation increase again, but the level of significance is attained only by the correlation coefficient calculated for the left sided eyeball compression. It should be noted that with an increase in strength of afferent stimulation changes in correlation coefficients calculated for both bilateral and unilateral compressions of the eyeballs are basically the same.

The correlations between the resting blood pressure and magnitude of depressor effects found in individual stimulation intensities are in general positive, indicating that changes in the blood pressure evoked by both unilateral and bilateral compression of the eyeballs follow the WILDER's 'law of initial value' 8,9 . This rule is also followed by the depressor effects evoked by different doses of acetylcholine ${ }^{3}$, but its mode of operation is quite different in both instances. Contrary to the results of experiments presented above, the correlations calculated for blood pressure effects induced by acetylcholine display a steady increase with an increase in dose of this drug. The cause of these differences remains unclear, but it may be surmized that they are related to different modes of activation of the mechanisms governing the appearance of the depressor responses.

On the other hand, the changes observed in magnitude of correlation coefficients are very similar to those of the gain of the depressor effects studied ${ }^{7}$, the maximal values of both parameters being situated very closely to one another in the middle of the intensity range applied in these studies. It is possible that the maximal gain is observed just when the activation of mechanisms deciding the magnitude of depressor responses is at its maximum. The analogies in the course of the gain and of the correlation coefficients may indicate that, for revealing the significant relationship between the resting blood pressure and magnitude of depressor responses, a strictly determined intensity of afferent stimulation is required.

Résumé. Les corrélations entre le niveau de repos de la pression artérielle et le degré des effets dépressifs provoqués par la compression des yeux sont positives. Leur valeur dépend de l'intensité de la stimulation. Elle atteint son maximum à une intensité semblable à celle qui conditionne la plus forte amplification des réactions étudiées.

\section{A. Niechaj and E. Modrzejewski}

Department of Human Physiology, Medical School, Lublin (Poland), 6 April 1970.
1 B. Korou and M. L. Brown, Archs int. Pharmacodyn. Thér. 170, 371 (1967).

2 B. Korol and M. L. Brown, Am. J. Physiol. 213, 112 (1967).,

3 A. Niechaj and I. Tychowska, Folia biol., Kraków 77, 271 (1969).

4 G. Prochnik, G. L. Marson and J. W. Stutzman, Am. J. Physiol. $762,553(1950)$.

5 H. F. Hardman, W. H. Baird, D. B. Sutts and B. K. B. Lum, Am. J. Physiol. 796, 445 (1959).

6 O. J. Nissen, Acta physiol. scand. 63, 68 (1965).

7 A. Niechaj and E. Modrzejewski, Acta physiol. pol. 19, 843 (1968).

8 J. Wilder, Expl. Med. Surg. 75, 47 (1957).

9 J. Wilder, Ann. N.Y. Acad. Sci. 98, 1211 (1962). 